\title{
Comparing the Response Burden between Paper and Web Modes in Establishment Surveys
}

\author{
Georg-Christoph Haas ${ }^{1}$, Stephanie Eckman ${ }^{2}$, and Ruben Bach ${ }^{3}$
}

\begin{abstract}
Previous research is inconclusive regarding the effects of paper and web surveys on response burdens. We conducted an establishment survey with random assignment to paper and web modes to examine this issue. We compare how the actual and perceived response burdens differ when respondents complete a survey in the paper mode, in the web mode and when they are allowed to choose between the two modes. Our results show that in the web mode, respondents have a lower estimated time to complete the questionnaire, while we do not find differences between paper and the web on the perceived response time and perceived burden. Even though the response burden in the web mode is lower, our study finds no evidence of an increased response burden when moving an establishment survey from paper to the web.
\end{abstract}

Key words: Perceived burden; experimental design; mode effects.

\section{Introduction}

Data on establishments are essential for monitoring national and international economies, for example, to help managers make decisions and enable politicians to craft informed policies (Jones et al. 2013). A large proportion of establishment data originates from surveys. However, for most establishments, responding to a survey is a task unrelated to business production, which potentially takes employee time away from other essential tasks (Willimack and Nichols 2010). This article is particularly concerned with response burden, which unfortunately is loosely defined in the literature (Yan et al. 2020). We define response burden as the strain experienced by respondents while they respond to a survey. Factors affecting response burden are multifaceted and include questionnaire design, content and length, question wording, and the data collection mode.

When the response burden is high, respondents have difficulties answering a questionnaire (Couper and Groves 1996). In establishment surveys, a high response burden is associated with low data quality and high data collection costs (e.g., Bavdaž et al. 2015; Jones 2012; Giesen 2012; Giesen et al. 2011; Hedlin et al. 2005; Haraldsen and Jones 2007). A high burden can also lead to more data editing and fewer timely responses (e.g., Haraldsen and Jones 2007; Berglund et al. 2013; Giesen 2013a) and may reduce respondents' motivation and efforts to answer correctly (Krosnick 1991).

\footnotetext{
${ }^{1}$ Institute for Employment Research (Institut für Arbeitsmarkt- und Berufsforschung), Statistical Methods, Regenburger Straße 100, Nürnberg, 90478, Germany. Email: georg-christoph.haas@iab.de

${ }^{2}$ RTI International (Statistical Methods), 701 13th St NW, Suite 750, Washington, D.C. 20005, U.S.A. Email: seckman@rti.org

${ }^{3}$ University of Mannheim, B5, Mannheim, 68159, Germany. Email: r.bach@uni-mannheim.de
} 
One way to reduce the response burden in establishment surveys may be to change the survey mode from paper to the web. The web mode offers many advantages that can reduce the response burden. However, it can also introduce response burden if respondents are not comfortable with website navigation and forms. In practice, many surveys offer a choice of web or another mode, often paper. The choice of mode may allow respondents to choose their preferred mode, leading to a lower burden; or it may present respondents with another decision they must make, leading to a higher burden, as in Medway and Fulton (2012). Studies of the change in the response burden when moving establishment surveys from paper to the web have found that the introduction of the web mode reduces the response burden (Giesen 2013b; Gravem et al. 2011; Giesen et al. 2009) or has no effect (Snijkers et al. 2007). However, because the questionnaire content and structure in those studies also changed, we cannot draw a definitive conclusion on the effect of web on response burden (Gravem et al. 2011).

To address the shortcomings of previous studies, we conducted an establishment survey with an experimental assignment to the mode: Paper-only, Web-only or concurrent Paper and Web mixed mode. We examine the differences in response burden between modes, and we will answer the following two research questions:

1. Is response burden in an establishment survey lower in the web mode than it is in the paper mode?, and

2. Do respondents experience a lower burden if they can choose between the paper and the web mode?

To answer our research questions, we first define what type of response burden we evaluate. Second, by listing the benefits of the web mode, we explain why data collection agencies are interested in using the web mode for their establishment surveys. Third, we provide a literature overview on how response burden is measured. Fourth, we describe the possible effects of paper and the web on response burden, leading us to our hypotheses. Fifth, we describe our data, including our study and experimental design as well as key features of our web survey. Sixth, we describe the models we use to evaluate response burden differences. Seventh, we present our results. Finally, we summarize our results and the limitations of their scope.

\section{Background}

Establishment surveys can impose burden in three ways (Löfgren 2011; Haraldsen et al. 2013). First, each time an establishment is selected for a survey, the establishment is burdened with a response request, and large establishments are selected more often than medium-sized and small establishments (Jones 2012). Second, for those establishments that choose to participate, the participation costs are presumably greater than the benefits to the establishment (Verkruyssen and Moens 2011; Giesen 2011). As a result, establishments may have a low motivation to respond. Third, instrument design introduces burden through questionnaire content and length, the data collection mode (e.g., face-toface, telephone, paper, and web), the wording of questions and other factors. This article focuses on burden introduced through instrument design. We refer to this type of burden as response burden. Specifically, we focus on the mode as part of the instrument design and 
compare the difference in response burden between paper and web modes in establishment surveys.

In the remainder of this section, we provide a short overview of the benefits of web surveys compared to paper surveys. We explain how response burden is conceptualized and measured, and the possible effects of paper and web surveys on response burden. We then develop hypotheses regarding how response burden differs between paper and web surveys.

\subsection{Benefits of Web Surveys}

Although paper and web are both cost-efficient self-administered modes, web offers several advantages over paper. Web surveys reduce or eliminate mailing costs. Many establishment survey invitations can be sent via email; when mail invitations are used, only an invitation letter is sent rather than a large paper questionnaire and return envelope. Furthermore, web surveys reduce data entry costs. These savings usually more than offset potential increases in programming needed to set up the web survey.

The web mode can also increase data quality. Web questionnaires can provide feedback to respondents (Couper 2008; Conrad et al. 2007). If respondents submit an unlikely answer, plausibility checks can ask respondents to re-evaluate their answers, which could reduce the need for data editing. Furthermore, researchers can offer definitions and additional information on how to answer the question. Future web surveys may even include chatbots that can address respondents' questions during the response process (Lagerstøm 2018). Additionally, the web mode can manage calculation and counting tasks, which simplify responses (Giesen et al. 2009; Giesen 2007). Especially in establishment surveys, which often require responses from multiple respondents, web surveys may simplify the response process within the establishment as respondents can easily distribute a link for a web survey via email, while a paper questionnaire is more cumbersome to distribute to multiple respondents. Finally, web surveys enable a complex filter and skip pattern design while only showing items applicable to each respondent.

\subsection{Conceptualizing and Measuring Response Burden}

Bavdaž et al. (2015) summarize three reasons why National Statistical Institutes (NSIs) should consider response burden when designing data collection programs. The first is political: responding to a survey takes time away from an establishment's core business and may decrease competitiveness. The second is methodological: a high burden may reduce data quality and increase data collection costs. The third is strategic: burden can negatively affect the relationship between NSIs and the business community, reducing the motivation to respond to surveys. Therefore, NSIs should monitor and reduce burden to the fullest extent possible (e.g., see European Commission 2011), and burden management has become a key element for NSIs (e.g., see Giesen et al. 2018).

Response burden is a multifaceted concept influenced by motivation, task difficulty, survey effort and respondent perception (Yan et al. 2020). It is often "loosely defined", and Yan et al. argue for a unified concept of response burden. For our study, we follow the conceptualization of actual and perceived response burden, which we find is the most prominent within the establishment survey literature (e.g., Giesen 2013a; Berglund et al. 
2013; Hedlin et al. 2005; Giesen et al. 2009; Giesen and Burger 2013; Haraldsen and Jones 2007). The literature suggests several indicators to measure actual response burden. Because respondents need time to read, think, and respond to a question, each item in the survey adds to the overall burden (Bradburn 1978). Therefore, questionnaire length is probably the most basic indicator for response burden (see, e.g., Groves et al. 1992; Van Loon et al. 2003). In our study, we asked respondents how much time they spent answering the questions (see, e.g., Dale et al. 2007; Giesen et al. 2011; Giesen 2013b). Additional indicators used by NSIs to track response burden imposed on establishments include the following: calls to the service number, requests for help, response rates, and average time for questionnaire completion (Downey et al. 2007; Snijkers et al. 2007; Sear 2011; Giesen et al. 2011).

Perceived response burden is a subjective measure of respondents' experiences responding to the survey, for example, as burdensome and time consuming (see, e.g., Haraldsen et al. 2013). It is not the actual time spent taking a survey but the perception of the time and effort of the survey that affects respondents' survey experience and response quality (e.g., Haraldsen and Jones 2007). Many factors can contribute to perceived response burden: structures within the establishment (who has the information needed to respond), the timing of a survey (during a firm's busy period or while a key informant is on vacation), question design, data collection mode, number of survey invitations, difficulty of the response task, and attitudes towards the data collector (Hedlin et al. 2005; Giesen 2013b).

Perceived response burden is often collected with two items. One item asks for the perception of time on a five-point scale, that is, if respondents perceive the survey as quick or time-consuming. The other item asks for the perception of burden on a five-point scale, for example, if respondents perceive the questionnaire as easy or burdensome to answer (see, e.g., Dale et al. 2007; Giesen et al. 2011; Giesen 2013b). We use the same perceived response burden indicators for our study.

Actual and perceived response burdens are conceptually different from each other but positively correlated (Giesen 2013a; Berglund et al. 2013). If respondents perceive a questionnaire as difficult, the actual response burden (time spent) is also likely high (Giesen 2013a). Giesen et al. (2011) found that 34 of 41 NSIs collect data on actual response burden, while 12 collect data on perceived response burden. We examine how assigned mode and mode choice affect both actual burden and perceived burden.

\subsection{Possible Effects of Paper and Web Surveys on Response Burden}

The impact of mode on actual and perceived burden is complex. Each page of a paper questionnaire introduces an additional workload, and respondents may perceive multipage questionnaires as burdensome. Even if not all questions apply to the respondent, the number of pages can make the survey seem overwhelming. Skip instructions in paper questionnaires may not be clear to respondents, and they may have a hard time navigating a paper survey. Web surveys, on the other hand, do not show all questions to the respondent but only those that apply. As a result, respondents never see the entire questionnaire and cannot immediately assess its total length. They also do not need to pay attention to filter instructions, which reduces the respondent's cognitive effort.

On the other hand, the web mode could increase response burden. Respondents with lower online skills may experience a greater burden (Gregory and Earp 2007). A poorly 
designed instrument can be difficult or frustrating to fill out. Furthermore, even welldesigned plausibility checks may increase response burden (Hedlin et al. 2005).

Most NSIs do not use web as a standalone mode but in combination with other modes of survey data collection, often a paper mode. Offering the web in addition to paper may reduce the perceived response burden: faced with a choice of mode, respondents should choose the mode they feel most comfortable responding to and the one that is lower burden for them (Erikson 2007). Lyly-Yrjänäinen and Van Houten (2011) propose offering multiple modes to reduce the respondent burden in Eurostat establishment surveys. However, offering multiple modes can overwhelm respondents and reduce response rates (Medway and Fulton 2012). Requiring respondents to choose a mode before they can begin the survey may also impose an additional burden on respondents.

\subsection{Hypotheses}

The above discussion leads us to several hypotheses regarding the relationship between the mode and response burden in establishment surveys. In accordance with the findings from earlier research (Gravem et al. 2011; Giesen et al. 2009; Snijkers et al. 2007), we hypothesize that burden will be lower for respondents assigned to the web mode than for those assigned to the paper mode (hypothesis 1).

Therefore, compared to the paper mode, we expect:

- a shorter time to complete the questionnaire in the web mode (hypothesis 1.1)

- a lower perceived time in the web mode (hypothesis 1.2)

- a lower perceived burden in the web mode (hypothesis 1.3)

Hypothesis 2 relates to mode choice: when respondents can choose their mode, they are likely to experience a lower burden than respondents who respond in the same mode but were not given a choice. We hypothesize that actual and perceived response burden among those who choose the web mode from a mixed-mode condition are lower than burden among those assigned to the web mode (hypothesis 2.1). Therefore, compared to the assigned web condition, we expect:

- a shorter time to complete the questionnaire by web respondents in the mixed-mode condition (hypothesis 2.1.1)

- a lower perceived time by web respondents in the mixed-mode condition (hypothesis 2.1.2)

- a lower perceived burden by web respondents in the mixed-mode condition (hypothesis 2.1.3)

Similarly, we expect lower actual and perceived response burden for respondents in the paper mode from a mixed-mode condition compared to respondents from the assigned paper condition (hypothesis 2.2). That is, compared to the assigned paper condition, we expect:

- a shorter time to complete the questionnaire by paper respondents in the mixed-mode condition (hypothesis 2.2.1)

- a lower perceived time by paper respondents in the mixed-mode condition (hypothesis 2.2.2)

- a lower burden by paper respondents in the mixed-mode condition (hypothesis 2.2.3) 
Although respondents likely use their preferred mode when choosing between paper and web, we should still see differences in response burden between those choosing paper and those choosing web. The features of the web mode described earlier should reduce response burden. Therefore, we hypothesize that actual and perceived response burden will be lower for those who respond via the web in the mixed-mode condition than for those who respond via paper in the mixed-mode condition (hypothesis 3). Therefore, compared to those choosing paper, we expect:

- a shorter time to complete the questionnaire for those choosing web (hypothesis 3.1)

- a lower perceived time for those choosing web (hypothesis 3.2)

- a lower perceived burden for those choosing web (hypothesis 3.3)

\section{Data}

To examine our hypotheses regarding the differences in response burden between modes, we use data from a German establishment survey. The Institute for Employment Research (IAB) designed this survey to evaluate the effect of the mode on the data quality in establishment surveys.

Overall, 16,000 establishments were sampled from German administrative records. Sample selection was stratified by location (East and West Germany), establishment size class ( $<10$ employees, 10-199 employees, and $\geq 200$ employees) and industry class following the German Classification of Economic Activities (Destatis 2008). Establishments already selected for IAB surveys in 2015 were removed from the frame before selection to avoid causing any problems for those ongoing data collection efforts. The removed establishments were random selections from the frame and thus should not bias the sample. However, there are some strata where no unselected establishments remained on the frame. This issue particularly affected the largest size class in which there are few establishments. For this reason, the sample used in this study is not fully representative of the population of establishments, but efforts were made to be as complete as possible given the need to avoid overlap with ongoing surveys. Participation in the survey was voluntary, and the overall response rate was $10.2 \%$ (AAPOR RR1, according to AAPOR standard definitions, see AAPOR 2016) with 1,574 establishments responding.

All sampled establishments were randomly assigned to one of the three mode conditions (Paper-only, Web-only, Choice). To ensure we would have enough cases in all three mode groups and within the two modes in the Choice group, we assigned one-fourth of the establishments in our sample to Paper-only, one-fourth to Web-only and two-fourths to Choice.

We prepared two versions of the questionnaire with different topics, number of items and question formats. One version focused on the consequences of the introduction of the federal minimum wage in Germany in 2015. We refer to this version as Minimum Wage. Another version contains questions about the effect of increasing digitalization on labor markets. We refer to this version as Digitalization. We randomly assigned each sampled establishment to one of the two versions. Therefore, both versions are independent surveys with the same experimental mode design. However, our hypotheses should apply to both questionnaire versions. In fact, seeing similar results over both versions should increase the reliability of our results. All mode groups were invited to participate in the study via a 
mailed letter. For the Paper-only group, we mailed establishments a cover letter with information about the study and a paper questionnaire. Depending on the assigned versions, the number of pages and questions differed slightly. The Minimum Wage questionnaire contained 74 questions on 20 pages. In contrast, the Digitalization questionnaire had 69 questions on 19 pages, printed in a 20-page booklet. Therefore, the difference in page volume between both versions was negligible.

For the Web-only group, we sent establishments a cover letter with information about the study, a link and the request to fill out our online questionnaire. To isolate mode effects, we took care to ensure that the paper and web questionnaire were visually similar to each other. However, the web mode offers functionalities that may reduce response burden, as discussed above. We implemented six web survey functionalities. First, the web survey presented questions in a paging design (one question on each page) so that respondents would not miss a question. Second, the web survey used automatic skips, that is, questions that did not apply to respondents were not shown. Third, the question about the number of different employment groups automatically summed and displayed the total number of employees. Fourth, we implemented plausibility checks. For instance, if the respondent stated that the regular weekly working hours were greater than the legal limit of 48 hours, the web survey prompted an error message in red that asked respondents to reevaluate their answer. The number of plausibility checks differed by questionnaire version: Minimum Wage contained up to 13 plausibility checks, and Digitalization contained up to five plausibility checks. Fifth, at the end of each section, respondents were able to print the questionnaire section with their responses for their own documentation.

Sixth, the web survey contained an index that allowed respondents to navigate to specific sections. The index indicated the structure of the questionnaire and showed the headings for each section (see Figure 1). After finishing a section, the web survey redirected respondents to this index page. The index page gave respondents an understanding of what part of the questionnaire should be answered by whom in the establishment. In establishment surveys, respondents sometimes do not have the

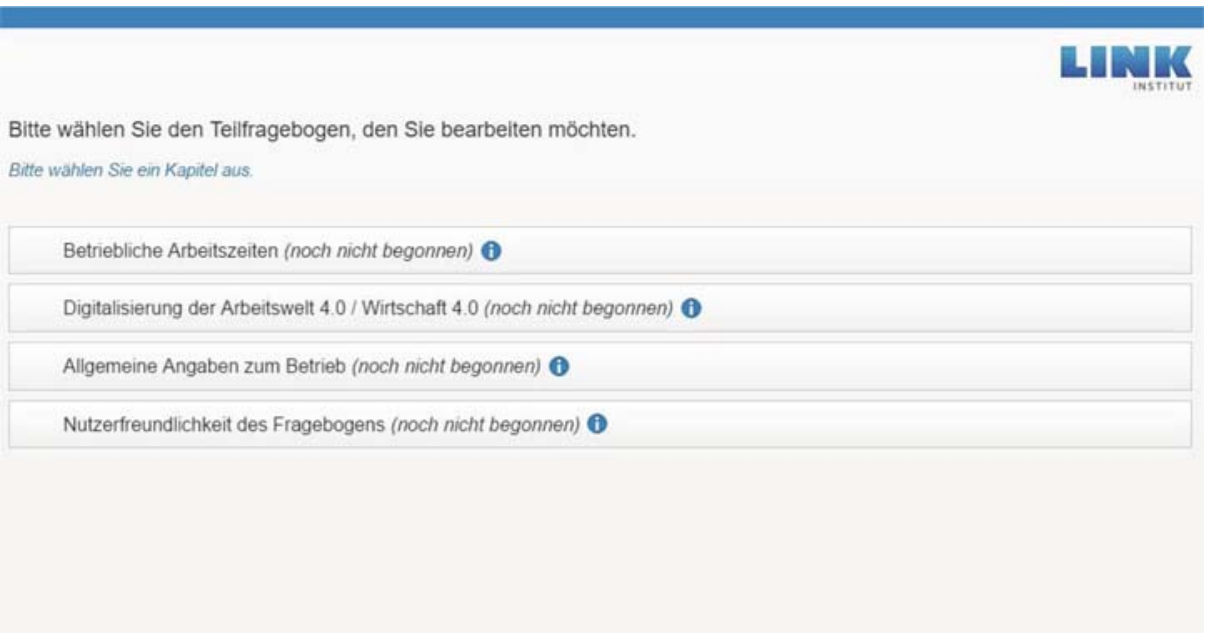

Fig. 1. Index page for the web survey in the digitalization version. 
information required to answer all questions. Therefore, they require help from colleagues to answer some questions.

For the establishments in the Choice groups, we sent a cover letter and the same paper questionnaire as in the Paper-only group. The cover letter offered a web link and presented the option to choose between the paper and web modes.

Figure 2 shows the response rates (RR) for our three mode groups and two versions. In the figure, Choice-Paper refers to cases that chose to respond via the paper mode in the mixed-mode condition. Choice-Web refers to those that responded on the web. In both versions, response rates in the Web-only and Choice-Web groups are smaller than those in the Paper-only and Choice-Paper groups. The response rates are also lower in all conditions for the Digitalization survey than the Minimum Wage survey $(8.5 \%$ versus $11.9 \%$ ). Furthermore, we find that compared to Paper-only, the Choice group is not different in terms of response rates (13.7\% versus $13.9 \%$ in the Minimum Wage survey; $11.8 \%$ versus $11.7 \%$ in the Digitalization survey). (To calculate the response rate for Choice-Paper and Choice-Web, we split the response rate of Choice into the proportion of Choice-Paper and Choice-Web, that is, $R R_{\text {Choice }}=R R_{\text {Choice-Paper }}+R R_{\text {Choice-Web }}$.) These results contradict findings from meta-analyses where offering a choice between modes is burdensome enough to not participate (Medway and Fulton 2012). However, the metaanalysis did not include establishment surveys.

To check whether respondents in each mode group differ from each other, a nonresponse analysis for the variables location (East and West Germany), establishment size class ( $<10$ employees, 10-199 employees, and $\geq 200$ employees) and industry was conducted (see Haas et al. 2016). No systematic differences in nonresponse patterns between the mode groups were found.

Involving other people and managing the response process can be a burden to respondents. Overall, $16.2 \%$ of our respondents reported that they had help answering the questionnaire. Concerning the proportion of multiple respondents, a chi-squared test suggests no differences between the mode groups and questionnaire versions $\left(\chi^{2}{ }_{7}\right.$, $\mathrm{N}=1,663=5.6, \mathrm{p}<0.585)$.

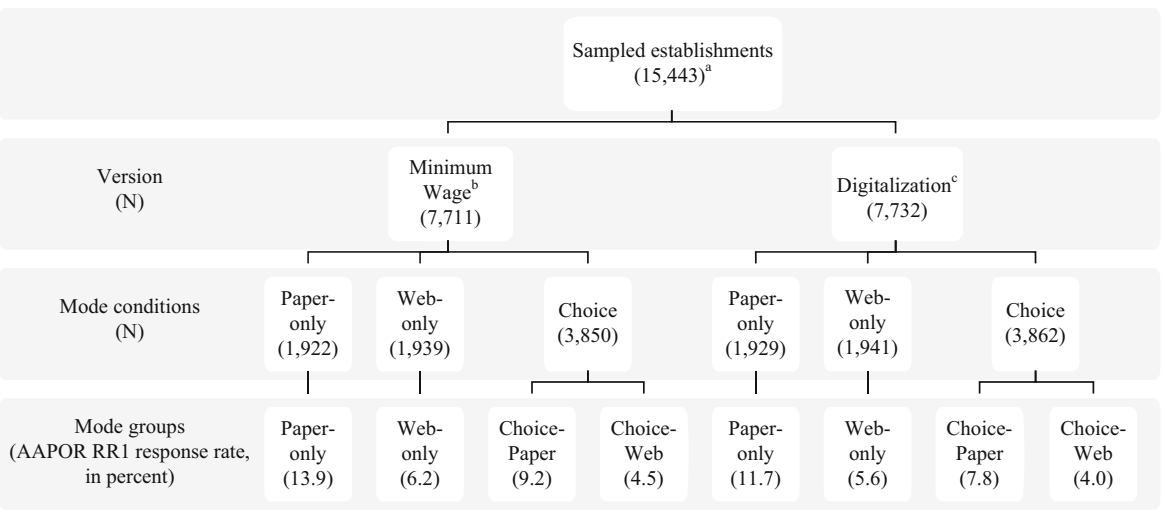

Fig. 2. Experimental assignment and response rates $(R R)$.

${ }^{\mathrm{a}}$ All Ns exclude 557 cases found to be ineligible.

${ }^{\mathrm{b}}$ Overall AAPOR RR1 for Minimum Wage is $11.9 \%$.

${ }^{\mathrm{c}}$ Overall AAPOR RR1 for Digitalization is $8.5 \%$. 


\section{Methods}

To evaluate the differences in response burden between survey modes, we use median and ordered regression models. The dependent variables in all models are measures of response burden. The independent variables are the experimental conditions (mode and topic) and control variables about the establishments (size class, industry, and East versus West Germany).

\subsection{Response Burden Variables}

We measure actual and perceived burden with three questions (Dale et al. 2007) asked at the end of the questionnaire. First, we asked respondents to estimate the time they needed to complete the questionnaire. The question required an answer in hours and minutes and has been used as a measure of actual burden in earlier studies (e.g., Dale et al. 2007; Giesen 2013a; Berglund et al. 2013). However, as respondents retrospectively estimate time and do not actively measure it, our measure of actual burden is not as objective as the literature may suggest. Second, we asked respondents to rate the perceived time taken on a five-point scale from "very quick" to "very time consuming". Third, we asked respondents to rate the burden of the survey on a five-point scale ranging from "very easy" to "very burdensome". For the sake of simplicity, we will refer to these two variables as perceived burden indicators. Furthermore, we recode our scales from five points to three points $(0,1$ and 2) by collapsing the two categories at each end. The results are not substantially different between the five- and three-point scales, but the three-point scale makes it easier for the reader to interpret the results. For the full wording of the three burden questions and response options, see Appendix (Section 7) Table 4.

\subsection{Independent Variables}

We have four mode groups, that is, Paper-only, Web-only, Choice-Paper, and Choice$W e b$, which are our independent variables of interest. We can test our three hypotheses by comparing the four groups. First, we compare Paper-only and Web-only to test whether response burden is lower for web in an establishment survey (hypothesis 1). Second, we compare Paper-only and Choice-Paper as well as Web-only and Choice-Web to test whether having the chance to choose a mode affects response burden (hypothesis 2). Third, we compare Choice-Paper and Choice-Web to test whether response burden is lower among respondents who opted for the web mode (hypothesis 3 ).

The models also control for the number of questions the respondent answered. Due to filters and skip patterns, the number of questions each respondent answered was not tightly controlled, even within the same questionnaire version. Therefore, we introduce the variable number of applicable items for each respondent. This variable counts the number of items respondents should have answered from the start of the interview until the response burden questions. In the last section, we asked respondents which questionnaire sections they answered themselves (as opposed to which ones a colleague answered). If they reported that more than one person answered the questionnaire, we consider only the number of items that the final respondent answered in the model because that respondent was the one who answered the burden questions. Furthermore, we include the indicator of more than one respondent in the model as a dummy variable. 
The models also control for location, size and industry to account for possible selection bias between modes and to increase the precision of our estimates.

\subsection{Models}

To evaluate our hypotheses on response burden differences between modes, we use multivariate regression models. We ran a model for each of our three response burden variables: time to complete the questionnaire, perceived time and perceived burden. Furthermore, we ran our models for each questionnaire version separately. Therefore, we have six models. Because we do not claim to represent the population of establishments, all analyses are unweighted. Each model does include the three stratification variables as controls in all models; however, they are the only variables that influence the weights. Controlling for the components of sample weights is an alternative to the use of weights in regression analyses (Gelman 2007).

Because the dependent variables have different scales, we use different models. Our response burden variable time to complete the questionnaire has large outliers (see Table 1). For this reason, we use a median regression that is less susceptible to being influenced by very short and very long times than an ordinary least squares regression (e.g., Cameron and Trivedi 2005):

$$
y_{i}=M_{i}^{\prime} \beta_{M}+X_{i}^{\prime} \beta_{X}+\varepsilon_{i}
$$

where $y_{i}$ is the time to complete the questionnaire for a questionnaire version, $M_{i}^{\prime}$ is the mode group, $X_{i}^{\prime}$ are the controls and $\varepsilon_{i}$ are the unobserved variables or errors.

Using a median regression, we assume that $\left(\varepsilon_{i} \mid M_{i}^{\prime}, X_{i}^{\prime}\right)=0$, which implies that:

$$
\operatorname{MED}\left(y_{i} \mid M_{i}^{\prime}, X_{i}^{\prime}\right)=M_{i}^{\prime} \beta_{M}+X_{i}^{\prime} \beta_{X}
$$

The two perceived burden variables are ordinal scales, and we use ordinal logistic regression models with these variables (e.g., see Cameron and Trivedi 2005, 519 f.) and adapt our model as follows:

$$
y_{i}^{*}=M_{i}^{\prime} \beta_{M}+X_{i}^{\prime} \beta_{X}+\varepsilon_{i}
$$

\begin{tabular}{|c|c|c|c|c|c|c|c|c|c|c|}
\hline & \multicolumn{5}{|c|}{ Minimum wage } & \multicolumn{5}{|c|}{ Digitalization } \\
\hline & $\mathrm{N}$ & Mean & Median & Min & $\operatorname{Max}$ & $\mathrm{N}$ & Mean & Median & Min & Max \\
\hline Paper-only & 272 & 34.4 & 30 & 5 & 180 & 190 & 48.9 & 35 & 10 & 240 \\
\hline Web-only & 116 & 26.2 & 20 & 2 & 120 & 91 & 38.2 & 30 & 5 & 165 \\
\hline Choice-paper & 355 & 37.5 & 30 & 5 & 210 & 245 & 55.4 & 30 & 5 & 1,440 \\
\hline Choice-web & 171 & 32.1 & 20 & 1 & 210 & 123 & 44.9 & 30 & 1 & 1,200 \\
\hline Overall & 914 & 34.2 & 30 & 1 & 210 & 649 & 49.1 & 30 & 1 & 1,440 \\
\hline
\end{tabular}

Table 1. Summary statistics for the time to complete the questionnaire in minutes by questionnaire version and mode group. 


$$
Y_{i}=\left\{\begin{array}{l}
0 \text { if } y_{i}^{*} \leq \alpha_{0} \\
1 \text { if } \alpha_{0}<y_{i}^{*} \leq \alpha_{1} \\
2 \text { if } \alpha_{1}<y_{i}^{*}
\end{array}\right.
$$

where $y_{i}^{*}$ is one of our perceived burden indicators and $\alpha_{i}$ the threshold parameters that are obtained by maximizing the log-likelihood. We calculate the marginal effects in the probabilities as follows:

$$
\frac{\delta \operatorname{Pr}\left[y_{i}=j\right]}{\delta M_{i}^{\prime}}=\left\{F ^ { \prime } \left(\alpha_{j-1}-\left(M_{i}^{\prime} \beta_{M}+X_{i}^{\prime} \beta_{X}\right)-F^{\prime}\left(\alpha_{j}-\left(M_{i}^{\prime} \beta_{M}+X_{i}^{\prime} \beta_{X}\right)\right\} \beta_{M}\right.\right.
$$

where $F^{\prime}$ denotes the derivative of the cumulative distribution function of $\varepsilon_{i}$.

The independent variables in all models are the same. Table 2 summarizes the six models. Because we focus on the differences between modes, we report only the linear prediction of the median time from the median regression $\left(\frac{\operatorname{MED}\left(\mathrm{y}_{\mathrm{i}} \mid \mathrm{M}_{\mathrm{i}}^{\prime}, \mathrm{X}_{\mathrm{i}}^{\prime}\right)}{\delta \mathrm{M}_{\mathrm{i}}^{\prime}}=\beta_{M}\right)$ and the predicted probabilities from the ordinal logistic regression (Equation (5)) for our mode groups.

The results of each model provide information supporting or rejecting our hypotheses. Running the models on the two questionnaire versions separately provides us with information about whether our results hold across both survey topics. Support for hypotheses 1.1 to 1.3 (response burden is lower in the web mode than in the paper mode) will be seen by comparing the coefficients of the mode indicators for Paper-only and Webonly. For the time to complete the questionnaire, we expect to see a lower estimated time for the Web-only group. For both perceived indicators, we expect to see higher predicted probabilities for the categories "quick" (perceived time) and "easy" (perceived burden) in the Web-only group. For hypotheses 2.1 .1 to 2.1.3, we compare the coefficients of ChoiceWeb against Web-only; and for hypotheses 2.2.1 to 2.2., we compare Choice-Paper and Paper-only. We expect a lower burden in the Choice conditions than in the Only conditions. For hypotheses 3.1 to 3.3, we compare the coefficients of Choice-Web against

\begin{tabular}{|c|c|c|c|c|}
\hline Model & $\begin{array}{l}\text { Dependent } \\
\text { variable }\end{array}$ & $\begin{array}{l}\text { Questionnaire } \\
\text { version }\end{array}$ & $\begin{array}{l}\text { Model } \\
\text { type }\end{array}$ & $\begin{array}{l}\text { Independent } \\
\text { variables }\end{array}$ \\
\hline 1 & Time to complete & Minimum wage & $\begin{array}{l}\text { Median } \\
\quad \text { regression }\end{array}$ & $\begin{array}{l}\text { - Mode } \\
\text { - Number of applicable }\end{array}$ \\
\hline 2 & Time to complete & Digitalization & & $\begin{array}{l}\text { items } \\
\text { - Establishment size }\end{array}$ \\
\hline 3 & Perceived time & Minimum wage & $\begin{array}{l}\text { Ordinal } \\
\text { logistic }\end{array}$ & $\begin{array}{l}\text { - Industry } \\
\text { - Region }\end{array}$ \\
\hline 4 & Perceived time & Digitalization & regression & $\begin{array}{l}\text { - Multiple respondents } \\
\text { (Yes/No) }\end{array}$ \\
\hline 5 & Perceived burden & Minimum wage & & $\begin{array}{l}\text { Interaction of mode } \\
\text { with each of the }\end{array}$ \\
\hline 6 & Perceived burden & Digitalization & & above (except mode) \\
\hline
\end{tabular}

Table 2. Summary of the six models for evaluating the response burden. 
Choice-Paper. We expect all three models to indicate lower burden in Choice-Web than Choice-Paper.

\section{Results}

Before presenting the results of our hypothesis tests, we examine the burden within the two questionnaire versions with the three response burden indicators (time to complete the questionnaire, perceived time and perceived burden).

On average, respondents to the Minimum Wage version needed less time to complete the questionnaire (34 versus 49 minutes) than respondents in the Digitalization version. As the data for the time to complete the questionnaire is not normally distributed (see Table 1), we cannot conduct a two-sample t-test. However, a nonparametric equality-of-medians test (see Snedecor and Cochran 1989) shows that complete time $\left(\chi_{1, \mathrm{~N}=1,563}^{2}=50.1, \mathrm{p}<\right.$ 0.001 ) is different between the two versions.

Table 3 shows the descriptive results of our perceived time indicators for each questionnaire version independent of the mode. We use a chi-squared test to examine differences in the perceived time indicators between our questionnaire versions. Overall, the Digitalization version is perceived as more time consuming $\left(\chi_{2, \mathrm{~N}}^{2}=1,668=32.0, \mathrm{p}<\right.$ $0.001)$ and burdensome $\left(\chi_{2, N}^{2}=1,660=54.6, \mathrm{p}<0.001\right)$ than the Minimum Wage version (see Table 4). Because burden is very different in the two questionnaire versions, we run separate models for the two versions in the rest of the article.

\subsection{Hypothesis 1: The Response Burden in the Web-only Mode is Lower than that in the Paper-only Mode}

We hypothesized that the web mode leads to a lower response burden. We test this hypothesis using the six models described in the methods section. For the time to complete the questionnaire, we expect to see a lower estimated time for the Web-only group than for the Paper-only group. For both perceived indicators, we expect to see higher predicted probabilities for the categories "quick" (perceived time) and "easy" (perceived burden) in the Web-only group compared to the Paper-only group.

Figure 3 compares the marginal effects of the four mode conditions on the median time to complete the questionnaire for the Minimum Wage version. At the median, respondents

Table 3. Proportions of perceived time and burden by questionnaire version.

\begin{tabular}{lcc}
\hline Perceived time* & Minimum wage $(\mathrm{N}=967)$ & Digitalization $(\mathrm{N}=701)$ \\
\hline Quick & 57.3 & 44.4 \\
Neither & 34.1 & 40.5 \\
Time consuming & 8.6 & 15.0 \\
\hline Perceived burden** & Minimum wage $(\mathrm{N}=962)$ & Digitalization $(\mathrm{N}=698)$ \\
\hline Easy & 66.6 & 49.0 \\
Neither & 29.0 & 42.1 \\
Burdensome & 4.4 & 8.9
\end{tabular}

${ }^{*} \chi^{2}=32.0, \mathrm{p}<0.001 ; * * \chi^{2}=54.6, \mathrm{p}<0.001$ 


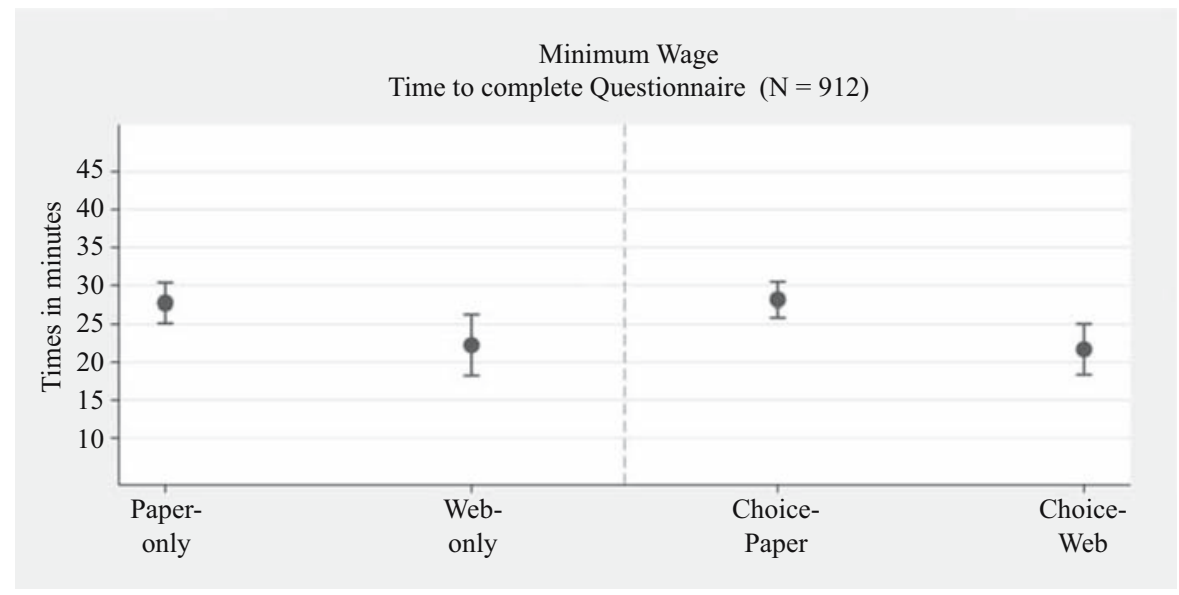

Fig. 3. Linear prediction of the estimated median time to complete the questionnaire in minutes for the minimum wage questionnaire (bars show $95 \%$ confidence intervals).

assigned to the Web-only group needed 5.5 fewer minutes to complete the questionnaire than respondents in the Paper-only group (based on self-reported completion time; $\left.\mathrm{F}_{1,886}=4.9, \mathrm{p}<0.013\right)$. As the time to complete the questionnaire is lower in the web group, the results support hypothesis 1.1 that the web mode has a lower actual burden than the paper mode.

Figure 4 shows the average predicted probabilities from the ordinal logistic regression model for respondents' perceived time and burden over the four mode groups in the Minimum Wage version. The predicted probabilities provide us with a measure of how the respondents perceived responding to the survey mode while controlling for our independent variables (size, industry, number of applicable items and region). The left panel shows the results for perceived time, and the right panel shows the results for

\section{Minimum Wage}
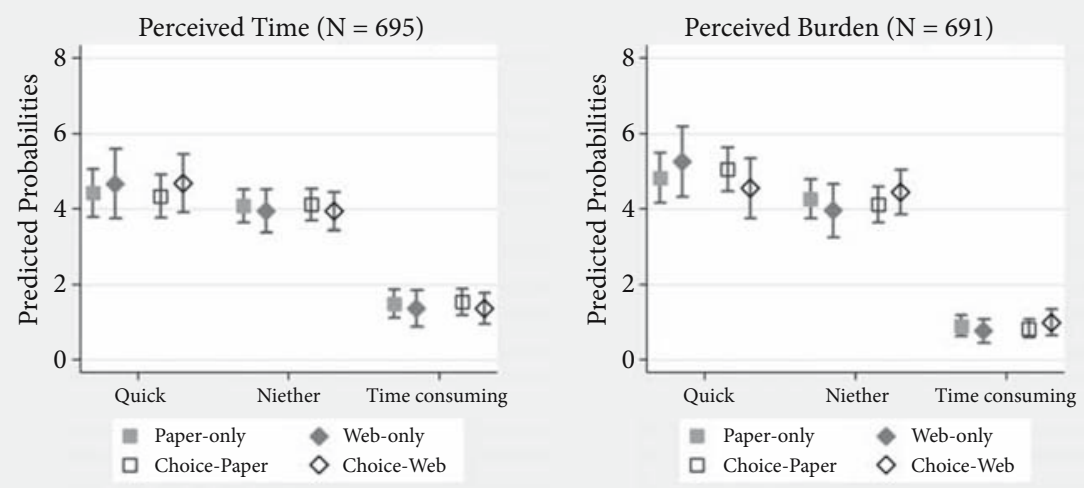

Fig. 4. Predicted probabilities from the ordinal logistic regression model for perceived time and perceived burden in the minimum wage version by mode group (bars show 95\% confidence intervals). 
perceived burden. Our model predicts similar probabilities for Paper- and Web-only for perceived time $\left(\hat{p}_{\text {quick }}=0.54-0.61, \hat{p}_{\text {neither }}=0.32-0.37\right.$, and $\left.\hat{p}_{\text {time consuming }}=0.07-0.09\right)$ and perceived burden $\left(\hat{p}_{\text {easy }}=0.64-0.72, \hat{p}_{\text {neither }}=0.25-0.31\right.$, and $\hat{p}_{\text {burdensome }}=0.03$ 0.05). We see no variation between Web-only and Paper-only for either of our perceived burden indicators $\left(\chi_{4, \mathrm{~N}}^{2}=409=3.2, \mathrm{p}=0.53\right.$ for perceived time and $\chi_{4, \mathrm{~N}}^{2}=409=0.7$, $\mathrm{p}=0.95$ for perceived burden). The results from the two perceived burden indicators do not support hypotheses 1.2 and 1.3.

The results for the Digitalization version are similar (see Figure 5 for the time to complete the questionnaire and see Figure 6 for perceived time indicators). Figure 5 shows that the estimated time for completing the questionnaire is ten minutes lower in Web-only $\left(\mathrm{F}_{1,615}=6.0, \mathrm{p}=0.007\right)$ and supports hypothesis 1.1 that response burden is lower for the web mode. In Figure 6, there is no variation in the marginal predicted probabilities between Web-only and Paper-only for perceived time $\left(\chi_{4, \mathrm{~N}=298}^{2}=0.1, \mathrm{p}=1.0\right)$ and perceived burden $\left(\chi_{4, \mathrm{~N}}^{2}=295=0.5, \mathrm{p}=0.97\right)$. Therefore, our results do not support hypotheses 1.2 and 1.3 that the perceived response burden is lower in the web mode.

\subsection{Hypothesis 2: The Burden is Lower when Respondents Choose a Mode than when that Mode is Assigned}

We hypothesized that the possibility of choosing one's preferred mode lowers the burden of respondents. Therefore, the estimated time should be smaller for the (2.1) Choice-Paper group than for the Paper-only and for the (2.2) Choice-Web group than the Web-only.

For the Minimum Wage version (see Figure 3), the difference between Paper-only and Choice-Paper in the time to complete the questionnaire is 0.4 minutes. In the group comparison of Web-only and Choice-Web, we find a 0.6-minute difference. For the Digitalization version (see Figure 5), there is no difference in the time to complete the questionnaire between the Paper-only and Choice-Paper groups and between the Webonly and Choice-Web groups.

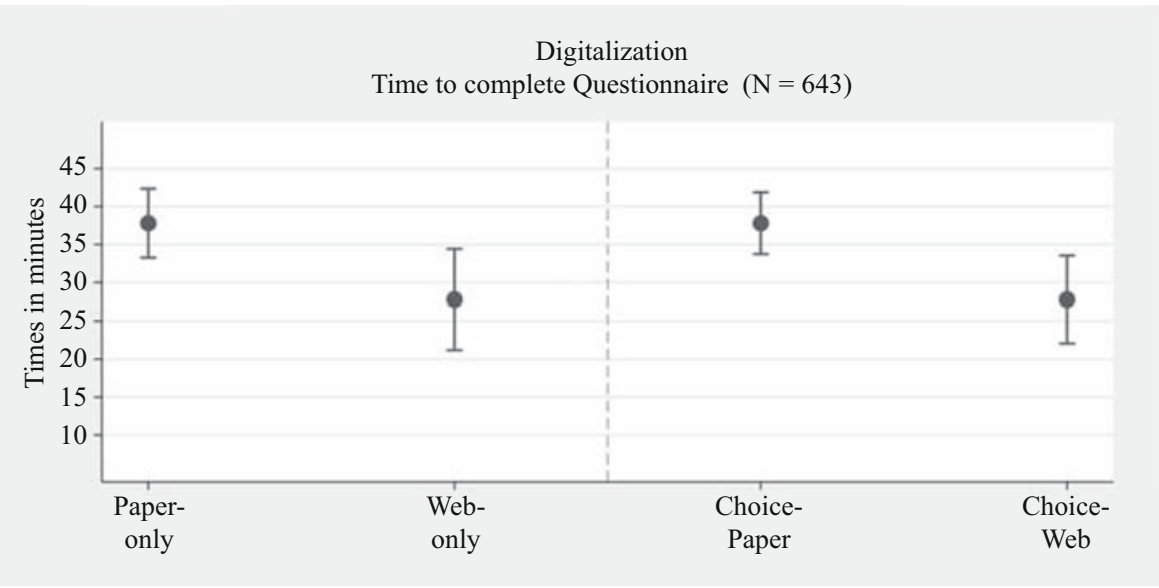

Fig. 5. Linear prediction of the estimated median time in minutes to complete the questionnaire for digitalization questionnaire (bars show $95 \%$ confidence intervals). 
For our perceived burden indicators (see Figure 4 for the Minimum Wage version and Figure 6 for the Digitalization version), there is no variation in the predicted probabilities between our Choice and Only groups (see Appendix Table 5 for the joint $\chi^{2}$ values). Overall, we find no support for our hypotheses 2.1.1 to 2.2.3.

\subsection{Hypothesis 3: The Response Burden in the Web Mode is Lower than that in the Paper Mode (mode Choice)}

Our third hypothesis is similar to the first, but it compares paper and the web when a choice is offered. We hypothesized that among those respondents given a choice, the web mode should have a lower response burden than the paper mode.

In the Minimum Wage questionnaire, Choice-Web respondents needed 6.4 fewer minutes to complete the questionnaire $\left(\mathrm{F}_{1,886}=9.5, \mathrm{p}=0.001\right)$ (see Figure 3 ) than Choice-Paper respondents. In the Digitalization questionnaire, the differences were larger: the estimated median time for completing the questionnaire is ten minutes lower in Choice-Web $\left(\mathrm{F}_{1,625}=7.6, \mathrm{p}=0.003\right)$ (see Figure 5).

Examining Figure 4 and Figure 6, we see no variation in the predicted probabilities between Choice-Paper and Choice-Web (see Appendix Table 5 for the joint $\chi^{2}$ values). Therefore, we find mixed support for our hypothesis: when offered a choice, those choosing the web mode have a lower estimated time for completing the questionnaire (hypothesis 3.1), but there is no difference in the perceived burden (hypotheses 3.2 and 3.3).

\section{Conclusion}

We designed this study to determine the differences in response burden between paper and web modes in a German establishment survey. We designed two surveys with the same experimental mode groups. To evaluate response burden, we used three measures

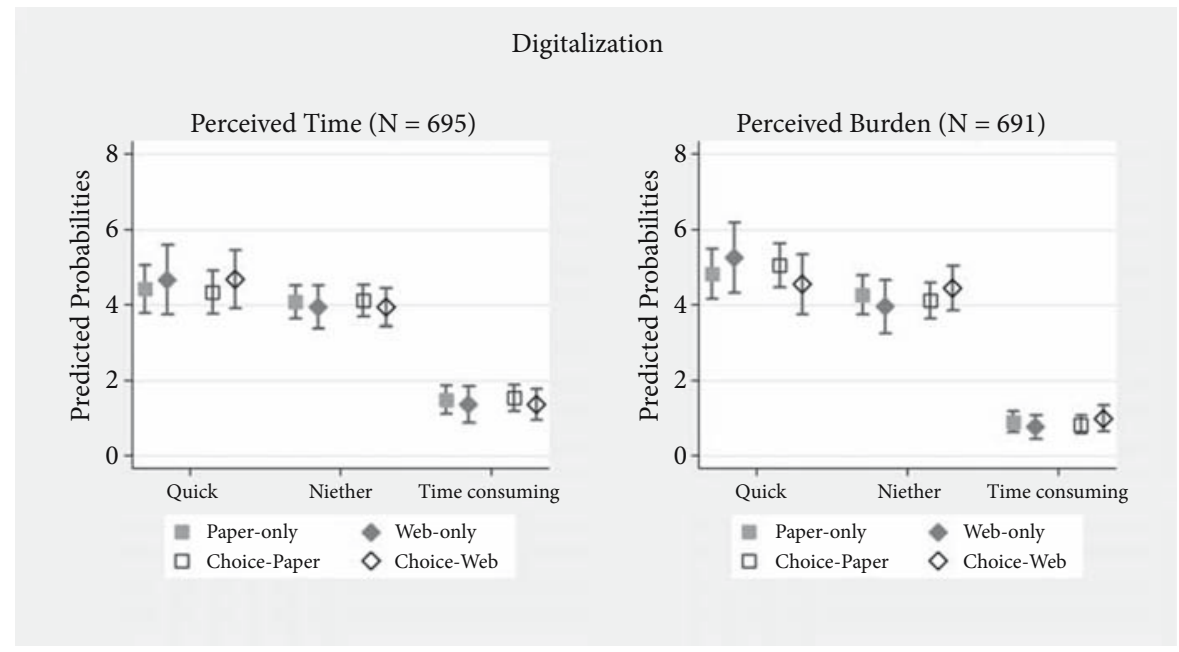

Fig. 6. Predicted probabilities from the ordinal logistic regression model for perceived time and perceived burden in the digitalization version by mode group (bars show 95\% confidence intervals). 
of burden (estimated time to complete the questionnaire, perceived time and burden) and four mode comparisons (Paper-only versus Web-only, Choice-Paper versus Paper-only, Choice-Web versus Web-only, Choice-Paper versus Choice-Web) to answer our research questions about whether response burden is lower in an establishment web survey and whether respondents feel less burdened if they can choose between paper and web modes.

This study has shown that web respondents, whether they were offered the web as a standalone mode or concurrently with a paper questionnaire, have a lower median time to complete the questionnaire compared to a paper questionnaire. These results held when respondents chose the web mode and when they were assigned to the web mode.

We found no evidence of a difference in either measure of perceived burden between the paper and web modes. As we have mentioned at the beginning of this article, response burden is a multifaceted concept. It is important to note that perceptions of burden could be affected by factors other than time. For instance, a questionnaire that seems relevant and straightforward to respondents might be less burdensome than a shorter but more difficult instrument.

Our results suggest that offering respondents the choice of their preferred mode has no effect on response burden compared to a single-mode setting. Therefore, concerning response burden, the web mode is a cost-effective alternative to the paper mode. Furthermore, the results of our study are consistent across two different topics: Minimum Wage and Digitalization. Therefore, our results may also be applicable to other surveys.

A reason why we find a lower estimated time for the time to complete the questionnaire may be that the web mode has an automatic questionnaire flow and does not show unnecessary questions to the respondents. However, the estimated time to complete could also indicate that web respondents are more satisfied than paper respondents. Future research needs to address this question.

One could argue that the lower response rate in the web survey is a sign that respondents find that mode more burdensome. However, there are several possible explanations for the lower response rate in the web mode. First, while the paper group received an invitation letter and a 20-page questionnaire, the web group received only a one-page invitation letter, which is easier to overlook. Second, the paper questionnaire may have served as a visible reminder to complete the survey in a way that the one-page letter did not. Third, we have anecdotal evidence from our pretest that some respondents had trouble entering the survey link in their web browser. Therefore, contact persons in the web group may have failed to participate because they could not access the web survey, a challenge that the contact persons in the paper group did not have to overcome. Response burden may not be the driving issue for lower response rates. However, researchers planning to use the web mode for their establishment survey should remember that administrating a web survey comes at a cost of lower response rates.

Finally, we need to consider a number of important limitations:

First, the generalizability of our results is limited to surveys with similar lengths and formats. Our results are especially limited to our web survey design. Web surveys with a different design may perform differently as they may have functions or design characteristics that impact the response burden. We designed our web survey to be visually very similar to the paper questionnaire. However, important design features may reduce 
respondents' burden in a web survey. Further research might explore how to reduce the response burden in the web mode.

Second, participation in the surveys used in this study was not mandatory. However, for a large proportion of establishment surveys, participation is required by law. Voluntary establishment surveys are likely to exclude establishments that are not motivated to respond or that anticipate a high response burden. Unfortunately, we can only speculate about the relationship between the anticipated response burden, the response rate and our mode groups. Inviting establishments to participate a web survey may exclude respondents who are not very savvy in using digital technologies and therefore decide not to participate. Establishments in the paper group may have cross-read the questionnaire or even started to respond but decided to not respond. As the choice between several modes is likely to overwhelm respondents to not respond at all (Medway and Fulton 2012), the choice of mode in a mandatory survey may add a perceived burden to respond. In all three mode groups, we may have found a higher response burden if the establishment survey would have been mandatory.

Third, there may be establishments with no internet access or with internal security guidelines that block web surveys or render them poorly (Harrel et al. 2007). Furthermore, establishments may have problems logging in, finding the website or navigating the survey (Bremner 2011; Gregory and Earp 2007). Therefore, our web respondent sample may be biased by an unknown coverage error.

Fourth, offering a paper, web or paper/web survey may recruit different kinds of respondents. Therefore, our respondent sample may be biased by mode-introduced nonresponse not visible in the data. However, the fact that the differences between paper and the web in the Only groups and paper and the web in the Choice groups are similar and the fact that our findings are consistent over two questionnaire versions makes us somewhat confident in the validity and reliability of our results.

Fifth, our results only consider German establishments. The results may change in establishment populations with higher or lower digitalization rates or with higher or lower internet penetration rates. Furthermore, we can link our results only to establishments that finished the survey but not to all invited establishments.

Sixth, we only consider the effect of the paper and web modes and not any other mode; instrument design; or interaction between instrument designs, respondent characteristics and establishment structures such as size. Especially in relation to the mode, instrument design decisions, respondents' characteristics and establishment structures can interact with each other. As we know from surveys of individuals, younger, more affluent, and higher educated respondents prefer the web mode over the paper mode (Kaplowitz et al. 2004; Kwak and Radler 2002; Messer and Dillman 2010; Millar et al. 2009). Similar effects may occur in establishment surveys. Our sample does not allow testing for these interactions as the number of cases is insufficient. The interaction of the web mode with other survey properties, respondent characteristics and establishment structures should be evaluated in future research.

Seventh, independent of the mode, first-time respondents must become familiar with the survey instrument. Against this background, respondents will develop individual best practices on how to interact with the survey instrument, that is, they improve when responding to a mode each time they participate. Therefore, we may see a change in the response burden 
over time. Future research should assess whether panel participation affects the response burden and whether the response burden decreases or increases over time in the web mode.

Eighth, we used a postal letter as the mode of contact to invite establishments in each mode group to participate. Using a different means for contact, for example, email, may affect respondents' perceived burden. To access a web survey, respondents usually use a link. If the link is provided within an email, respondents only need to click on that link to access the web survey. If the link is provided on a paper invitation letter, respondents should type the link into their browser search bar to access the web survey, which takes more effort than just clicking on a link. Therefore, in terms of the response burden, contacting establishments with postal letters may increase the burden.

Although these limitations seem numerous, our results provide important insights into the effect of the web mode on the response burden in establishment surveys. Moreover, we are convinced that the validity of our findings is very high due to our rigorous experimental manipulations. In addition, our findings are consistent across two different surveys, which increases the reliability of our results. Our study provides important findings for the development and design of establishment surveys in the online era. Even if the perceived response burden (for respondents) is not lower in the web mode, web surveys are cost effective and enable features that help to improve data quality. Our findings about response burden, combined with the lack of difference in the response rates between the Paper-only and the Choice conditions, lead us to recommend that surveys should offer establishments a choice of paper and web modes.

\section{Appendix}

Table 4. Wording and response options for the response burden indicators.

\begin{tabular}{|c|c|c|c|}
\hline Dimension & Indicator & Question & Response options \\
\hline \multirow[t]{2}{*}{$\begin{array}{l}\text { Perceived } \\
\text { burden }\end{array}$} & Perception of time & $\begin{array}{l}\text { Did you find it quick or } \\
\text { time consuming to fill } \\
\text { in the questionnaire? }\end{array}$ & $\begin{array}{l}\text { Very quick, Quite quick, } \\
\text { Neither quick nor time } \\
\text { consuming, Quite } \\
\text { time consuming, Very } \\
\text { time consuming }\end{array}$ \\
\hline & $\begin{array}{l}\text { Perception of } \\
\text { burden }\end{array}$ & $\begin{array}{l}\text { Did you find it easy or } \\
\text { burdensome to fill in the } \\
\text { questionnaire? }\end{array}$ & $\begin{array}{l}\text { Very easy, Quite easy, } \\
\text { Neither easy nor burden- } \\
\text { some, Quite burdensome, } \\
\text { Very burdensome }\end{array}$ \\
\hline $\begin{array}{l}\text { Actual } \\
\text { burden }\end{array}$ & $\begin{array}{l}\text { Time to complete } \\
\text { (if } 1+\text { persons } \\
\text { filled out the } \\
\text { questionnaire) }\end{array}$ & $\begin{array}{l}\text { How much time did you } \\
\text { spend on actually filling } \\
\text { in the questionnaire } \\
\text { (sections)? }\end{array}$ & $\begin{array}{l}\text { Number of hours, } \\
\text { Number of minutes }\end{array}$ \\
\hline
\end{tabular}


Table 5. Joint $\chi 2$ values from margin contrast for minimum wage and digitalization questionnaire versions and hypotheses 1-3.

\section{Minimum wage}

Digitalization

H1: lower estimated time

for web respondents

Perceived time

Perceived burden

$$
\begin{array}{ll}
\chi_{4, \mathrm{~N}=409}^{2}=3.2, \mathrm{p}=0.53 & \chi_{4, \mathrm{~N}=298}^{2}=0.1, \mathrm{p}=1.0 \\
\chi_{4, \mathrm{~N}=409}^{2}=0.7, \mathrm{p}=0.96 & \chi_{4, \mathrm{~N}=295}^{2}=0.5, \mathrm{p}=1.0
\end{array}
$$

H2.1: lower estimated time

for choice-paper respondents

Perceived time

Perceived burden

$$
\begin{array}{ll}
\chi_{4, \mathrm{~N}=655}^{2}=2.5, \mathrm{p}=0.64 & \chi_{4, \mathrm{~N}=461}^{2}=0.1, \mathrm{p}=1.0 \\
\chi_{4, \mathrm{~N}=652}^{2}=0.7, \mathrm{p}=0.94 & \chi_{4, \mathrm{~N}=457}^{2}=0.1, \mathrm{p}=1.0
\end{array}
$$

H2.2: lower estimated time

for choice-web respondents

Perceived time

$$
\begin{array}{ll}
\chi_{4, \mathrm{~N}=305}^{2}=1.2, \mathrm{p}=0.88 & \chi_{4, \mathrm{~N}=234}^{2}=0.0, \mathrm{p}=1.0 \\
\chi_{4, \mathrm{~N}=304}^{2}=1.5, \mathrm{p}=0.83 & \chi_{4, \mathrm{~N}=234}^{2}=1.0, \mathrm{p}=0.90
\end{array}
$$

Perceived burden

H3: lower estimated time

for choice-web respondents

Perceived time

$$
\begin{array}{ll}
\chi_{4, \mathrm{~N}=551}^{2}=0.66, \mathrm{p}=0.96 & \chi_{{ }_{4, \mathrm{~N}}=397}^{2}=0.7, \mathrm{p}=0.95 \\
\chi^{2}{ }_{4, \mathrm{~N}=547}=0.0, \mathrm{p}=1.0 & \chi_{4, \mathrm{~N}=396}^{2}=0.6, \mathrm{p}=0.96
\end{array}
$$

Perceived burden

${ }^{+} \mathrm{p} \leq 0.1, * \mathrm{p} \leq 0.05, * * \mathrm{p} \leq 0.01$, and $* * * \mathrm{p} \leq 0.001$

\section{References}

AAPOR. 2016. Standard Definitions: Final Disposition of Case Codes and Outcome Rates for Surveys. Available at: http://www.aapor.org/AAPOR_Main/media/publications/ Standard-Definitions20169theditionfinal.pdf (accessed March 2019).

Bavdaž, M., D. Giesen, S.K. Černe, T. Löfgren, and V. Raymond-Blaess. 2015. "Response burden in official business surveys: Measurement and reduction practices of national statistical institutes." Journal of Official Statistics 31: 559-588. https://doi.org/10. 1515/jos-2015-0035.

Berglund, F., G. Haraldsen, and Ø. Kleven. 2013. "Causes and consequences of actual and perceived response burden based on Norwegian data." In Comparative report on integration of case study results related to reduction of response burden and motivation of business, edited by D. Giesen, M. Bavdaž, and I. Bolko: 29-35.

Bradburn, N.M. 1978. "Respondent burden." In Proceedings of the Section on Survey Research Methods Section: American Statistical Association, August 14-17, 1978. 35-40. San Diego, USA. American Statistical Association: 35-40. Available at: http:// www.asasrms.org/Proceedings/y1978f.html (accessed March 2021).

Bremner, C. 2011. "An investigation into the use of mixed mode data collection methods for UK business surveys." In Proceedings of the BLUE-ETS Conference on Burden and Motivation in Official Business Surveys, edited by D. Giesen and M. Bavdaž. March 22-23, (pp. 217-220). Heerlen, The Netherlands: Statistics Netherlands. Available at: http://www.cbs.nl/NR/rdonlyres/23FD3DF5-6696-4A04-B8EF-1FAACE AD995C/0/ 2011proceedingsblueets.pdf (accessed March 2019). 
Cameron, A.C., and P.K. Trivedi. 2005. Microeconometrics: Methods and Applications. New York: Cambridge University Press.

Conrad, F.G., M.F. Schober, and T. Coiner. 2007. "Bringing Features of Human Dialogue to Web Surveys." Applied Cognitive Psychology 21: 165-187. DOI: https://doi.org/10.1002/acp. 1335.

Couper, M.P. 2008. Designing Effective Web Surveys. Cambridge: Cambridge University Press.

Couper, M.P., and R.M. Groves. 1996. "Household-level determinants of survey nonresponse." New Directions for Evaluation 70: 63-79. DOI: https://doi.org/10.1002/ ev.1035.

Dale, T., J. Erikson, J. Fosen, G. Haraldsen, J. Jones, and O. Kleven. 2007. Handbook for monitoring and evaluating business survey response burdens. Luxemburg: Eurostat. Available at: https://ec.europa.eu/eurostat/documents/64157/4374310/12-HANDBOOK-FOR-MONITORING-AND-EVALUATING-BUSINESS-SURVEY-RESONS E-BURDEN.pdf/600e3c6d-8e8d-44f7-a8f5-0931c71d9920 (accessed October 2021).

Destatis. 2008. Klassifikation der Wirtschaftszweige. Wiesbaden, Germany: Statistisches Bundesamt. Available at: https://www.destatis.de/DE/Methoden/Klassifikationen/Gueter-Wirtschaftsklassifikationen/klassifikation-wz-2008.html (accessed June 2019).

Downey, K., D. Mccarthy, and W. Mccarthy. 2007. "Encouraging the Use of Alternative Modes of Electronic Data Collection: Results of Two Field Studies." In Proceedings of the Third International Conference on Establishment Surveys, June 18-21, 2007. Montréal, Canada: 517-524. Available at: https://ww2.amstat.org/meetings/ices/2007/ proceedings/ICES2007-000168.PDF (accessed September 2019).

Erikson, J. 2007. "Effects of offering web questionnaires as an option in enterprise surveys." In Proceedings of the Third International Conference on Establishment Surveys, June 18-21, 2007. Montréal, Canada: 1431-1435. Available at: https://ww2. amstat.org/meetings/ices/2007/proceedings/ICES2007-000168.PDF (accessed September 2019)

European Commission. 2011. European Statistics Code of Practice for the National and Community Statistical Authorities. Adopted by the European Statistical System Committee, September 28, 2011. Available at: https://ec.europa.eu/eurostat/documents/ 3859598/5921861/KS-32-11-955-EN.PDF/5fa1ebc6-90bb-43fa-888f-dde032471e 15 (accessed September 2019).

Gelman, A. 2007. "Struggles with Survey Weighting and Regression Modeling." Statistical Science 22(2) : 153-164. DOI: https://doi.org/10.1214/088342306000000691.

Giesen, D. 2007. "Does mode matter? Comparing response burden and data quality of paper and an electronic business questionnaire." In Proceedings of the 6th Conference on Questionnaire Evaluation Standards (QUEST), April 24-26, 2007. Ottawa, Canada: 150-161. Available at: https://wwwn.cdc.gov/QBank/QUEST/2007/QUEST\%202007 \%20Proceedings-all\%20papers.pdf (accessed September 2019).

Giesen, D. 2011. "Burden reduction by communication." In Response Burden in Official Business Surveys: Measurement and Reduction Practices of National Statistical Institutes, edited by D. Giesen: 33-42.

Giesen, D. 2012. "Exploring Causes and Effects of Perceived Response Burden.” In Proceedings of the Fourth International Conference on Establishment Surveys, June 
11-14, 2012. Montréal, Canada. Available at: https://ww2.amstat.org/meetings/ices/2012/papers/302171.pdf (accessed September 2019).

Giesen, D. 2013a. "Causes and Consequences of Actual and Perceived Response Burden Based on Dutch Data." In Comparative report on integration of case study results related to reduction of response burden and motivation of business, edited by D. Giesen, M. Bavdaž, and I. Bolko: 33-39.

Giesen, D. 2013b. "Reducing Response Burden by Questionnaire Redesign.” In Comparative report on integration of case study results related to reduction of response burden and motivation of business, edited by D. Giesen, M. Bavdaž, and I. Bolko: 63-68.

Giesen, D., M. Bavdaž, and G. Haraldsen. 2011. "Response burden measurement: Current diversity and proposal for moving towards standardisation." In Proceedings of the BLUE-ETS Conference on Burden and Motivation in Official Business Surveys, edited by D. Giesen and M. Bavdaž. March 22-23: 125-134. Heerlen, The Netherlands: Statistics Netherlands. Available at: https://www.cbs.nl/-/media/imported/documents/2011/14/2011-4-4-4-2-giesen-et-al-presentation-blue-ets-2011.pdf (accessed March 2021).

Giesen, D., and J. Burger. 2013. "Measuring and understanding response quality in the Structural Business Survey questionnaires." In Proceedings of the European Establishment Statistics Workshop, September 9-11, 2013. Nuremberg, Germany. Available at: http://doku.iab.de/fdz/events/2013/Session5\%20Giesen.pdf (accessed September 2019).

Giesen, D., M. Morren, and G. Snijkers. 2009. "The effect of survey redesign on response burden: An evaluation of the redesign of the SBS questionnaires." Paper presented at the European Survey Research Association Conference 2009, June 29-July 3, 2009. Warsaw, Poland. European Survey Research Association.

Giesen, D., M. Vella, and C. Brady. 2018. "Response Burden Management for Establishment Surveys at Four National Statistical Institutes.” Journal of Official Statistics 34(2): 397-418. DOI: https://doi.org/10.2478/jos-2018-0018.

Groves, R.M., R.B. Cialdini, and M.P. Couper. 1992. "Understanding the decision to participate in a survey." Public Opinion Quarterly 56: 475-495. DOI: https://doi.org/ 10.1086/269338.

Gregory, G., and M. Earp. 2007. "Evolution of Web at USDA' National Agricultural Statistics Service." In Proceedings of the Third International Conference on Establishment Surveys (ICES-III), June 18-21, 2007. Montréal, Canada: 1442-1445. Available at: https://ww2.amstat.org/meetings/ices/2007/proceedings/ICES2007000192.PDF (accessed September 2019).

Gravem, D. 2011. "Response burden trends and consequences." In Proceedings of the BLUE-ETS Conference on Burden and Motivation in Official Business Surveys, edited by D. Giesen and M. Bavdaž. March 22-23: 221-236. Heerlen, The Netherlands: Statistics Netherlands. Available at: http://www.cbs.nl/NR/rdonlyres/23FD3DF5-66964A04-B8EF-1FAACEAD995C/0/2011 proceedingsblueets.pdf (accessed March 2019).

Haas, G.-C., S. Eckman, R. Bach, and F. Kreuter. 2016. "Is Moving Establishment Surveys from Mail to Web a Good or Bad Decision in Terms of Performance and Data Quality?" In Proceedings of the International Conference for Establishment Surveys 
2016 (ICES-V). June 21 -23, 2016. Geneva, Switzerland. Available at: https://ww2.amstat.org/meetings/ices/2016/proceedings/ICESV_TOC.pdf (accessed February 2020).

Haraldsen, G., and J. Jones. 2007. "Paper and Web Questionnaires Seen from the Business Respondent's Perspective." In Proceedings of the Third International Conference on Establishment Surveys (ICES-III), June 18-21, 2007, Montreal, Canada: 1040-1047. Available at: https://ww2.amstat.org/meetings/ices/2007/proceedings/ICES2007000259.PDF (accessed September 2019).

Haraldsen, G., J. Jones, D. Giesen, and L.C. Zhang. 2013. "Understanding and coping with response burden.” In Designing and Conducting Business Surveys, edited by G. Snijkers, G. Haraldsen, J. Jones, and D. Willimack: 219-252. Hoboken, NJ: John Wiley and Sons.

Harrell, L., H. Yu, and R. Rosen. 2007. "Respondent acceptance of web and E-mail data reporting for an establishment survey." In Proceedings of the Third International Conference on Establishment Surveys (ICES-III), June 18-21, 2007, Montreal, Canada: 1442-1445. Available at: https://ww2.amstat.org/meetings/ices/2007/proceedings/ICES2007-000230.PDF (accessed September 2019).

Hedlin, D., T. Dale, G. Haraldsen, and J. Jones. 2005. Developing Methods for Assessing Perceived Response Burden. Luxembourg: Eurostat. Available at: https://ec.europa.eu/ eurostat/documents/64157/4374310/10-DEVELOPING-METHODS-FOR-ASSESSING-PERCEIVED-RESPONSE-BURDEN.pdf/1900efc8-1a07-4482-b3c9-be88ee71 df3b (accessed October 2021).

Jones, J. 2012. "Response Burden: Introductory Overview Lecture.” In Proceedings of the Fourth International Conference on Establishment Surveys, June 11-14, 2012. Montréal, Canada. Available at: http://www.amstat.org/meetings/ices/2012/papers/ 302289.pdf (accessed September 2019).

Jones, J., G. Snijkers, and G. Haraldsen. 2013. "Surveys and Business Surveys." In Designing and Conducting Business Surveys, edited by G. Snijkers, G. Haraldsen, J. Jones, and D.K. Willimack: 1-33. Hoboken, NJ: John Wiley \& Sons.

Kaplowitz, M.D., T.D. Hadlock, and R. Levine. 2004. "A Comparison of Web and Mail Survey Response Rates." Public Opinion Quarterly 68: 94-101. DOI: https://doi.org/10.1093/poq/nfh006.

Krosnick, J.A. 1991. "Response strategies for coping with the cognitive demands of attitude measures in surveys." Applied Cognitive Psychology 5: 213-236. DOI: https:// doi.org/10.1002/acp. 2350050305.

Kwak, N., and B. Radler. 2002. "A Comparison between Mail and Web Surveys: Response Pattern, Respondent Profile, and Data Quality.” Journal of Official Statistics 18: 257-273. DOI: https://doi.org/10.1177/1525822X08317085.

Lagerstøm, B. 2018. "Chatbots as digital interviewers." Paper presented at the International Household Nonresponse Workshop, August 22-24, 2018. Budapest, Hungary

Löfgren, T. 2011. "Burden reduction by instrument design." In Response Burden in Official Business Surveys: Measurement and Reduction Practices of National Statistical Institutes, edited by D. Giesen: 43-50.

Lyly-Yrjänäinen, M., and G. van Houten. 2011. "Reduce burden, increase motivation. Main findings of the quality assessment of the second European company survey." In 
Proceedings of the BLUE-ETS Conference on Burden and Motivation in Official Business Surveys March 22-23, 2011, Heerlen, Netherlands, edited by D. Giesen and M. Bavdaž: 107-118. Available at: https://www.google.com/url?sa=t\&rct=j\&q=\& esrc $=$ s $\&$ source $=$ web $\& c d=\& v e d=2$ ahUKEwiFvfTm2OrzAhU8BWMBHYOIDv8Q FnoECAgQAQ\&url=https $\% 3 \mathrm{~A} \% 2 \mathrm{~F} \% 2 \mathrm{Fwww} . \mathrm{cbs} . \mathrm{nl} \% 2 \mathrm{~F}-\% 2 \mathrm{Fmedia} \% 2 \mathrm{Fimported} \%$ 2Fdocuments\%2F2011\%2F25\%2F2011-06-20-lyly-yrjanainen-van-houten-2011reduce-burden-increase-motivation.pdf\&usg=AOvVaw0n4dUPG4Ectn1K-baV7hE0 (accessed October 2021).

Medway, R.L., and J. Fulton. 2012. "When More Gets You Less: A Meta-Analysis of the Effect of Concurrent Web Options on Mail Survey Response Rates.” Public Opinion Quarterly 76: 733-746. DOI: https://doi.org/10.1093/poq/nfs047.

Messer, B.L., and D.A. Dillman. 2010. Using Address Based Sampling to Survey the General Public by Mail vs. "Web plus Mail". Technical Report 10-13. Social and Economic Sciences Research Center, Washington State University, Pullman. Available at: http://www.sesrc.wsu.edu/dillman/papers/2010/Messer\%20Dillman\%20WCSTechReport.pdf (accessed October 2021).

Millar, M.M., O.A.C. Neill, and D.A. Dillman. 2009. “Are Mode Preferences Real?" Technical Report of the Social and Economic Sciences Research Center. Pullman, Washington: Washington State University

Sear, J. 2011. "Response burden measurement and motivation at Statistics Canada." In Proceedings of the BLUE-ETS Conference on Burden and Motivation in Official Business Surveys Heerlen, March 22-23, 2011, Heerlen, Netherlands. edited by D. Giesen and M. Bavdaž: 151-160. Available at: https://www.cbs.nl/-/media/imported/documents/2011/25/2011-06-20-sear-2011-response-burden-measurement-and-motivation-at-statistics-canada.pdf (accessed October 2021).

Snedecor, G.W., and W.G. Cochran. 1989. Statistical Methods, (8th edition). Ames, IA: Iowa State University Press.

Snijkers, G., G. Haraldsen, A. Sundvoll, T. Vik, and H.P. Stax. 2011. "Utilizing web technology in business data collection: Some Norwegian, Dutch and Danish experiences." In Proceeding of the European Conference on New Techniques and Technologies for Statistics (NTTS), Brussels, Belgium

Snijkers, G., E. Onat, and R. Vis-Visschers. 2007. "The Annual Structural Business Survey: Developing and Testing an Electronic Form.” In Proceedings of the International Conference for Establishment Surveys 2007 (ICES-III) June 18-21, 2007, Montreal, Canada: 456-463. Available at: https://ww2.amstat.org/meetings/ices/2007/proceedings/ICES2007-000095.PDF (accessed October 2021).

Verkruyssen, F., and S. Moens. 2011. "Communication as a tool to reduce perceived response burden: Tips and tricks." In Proceedings of the BLUE-ETS Conference on Burden and Motivation in Official Business Surveys, March 22-23, 2011, Heerlen, Netherlands edited by D. Giesen and M. Bavdaž. 237-242. Available at: https://www.cbs.nl/-/media/imported/documents/2011/14/2011-4-4-8-1-verkruyssenmoens-presentation-blue-ets-2011.ashx?la=en-gb (accessed October 2021).

Willimack, D., and E. Nichols. 2010. "A Hybrid Response Process Model for Business Surveys." Journal of Official Statistics 26: 3-24. Available at: https://www.scb.se/- 
contentassets/ca21 efb41fee47d293bbee 5bf7be7fb3/a-hybrid-response-process-modelfor-business-surveys.pdf (accessed September 2021).

Van Loon, A.J.M., M. Tijhuis, H.S. Picavet, P.G. Surtees, and J. Ormel. 2003. "Survey Non-response in the Netherlands: Effects on Prevalence Estimates and Associations." Ann Epidemiol 13: 105-110. DOI: https://doi.org/10.1016/S1047-2797(02)00257-0.

Yan, T., S. Fricker, and S. Tsai. 2020. "Response Burden: What Is It and What Predicts It?" In Advances in Questionnaire Design, Development, Evaluation and Testing, edited by P.C. Beatty, D. Collins, L. Kaye, J.-L. Padilla, G.B. Willis, and A. Wilmot: 193-212.

Received September 2019

Revised February 2020

Accepted March 2021 